\title{
SEGURO COMPLEMENTARIO DE TRABAJO DE RIESGO EN PERSONAL DE SALUD
}

\section{COMPLEMENTARY OCCUPATIONAL RISK INSURANCE FOR HEALTH CARE PERSONNEL}

\author{
Manuel Landa-Romero ${ }^{1, a}$, \\ Cristiam Ramos-Ascona ${ }^{2, a}$, \\ Santiago Hidalgo-Contreras ${ }^{1, b}$
}

Sr. Editor. A propósito del artículo publicado en su revista en el número 2 del 2013, Mejia et al. informaron la deficiente cobertura de aseguramiento del personal médico del Servicio Urbano Marginal en Salud (SERUMS) ${ }^{(1)}$. Al respecto, es necesario comentar que en el Perú la seguridad social (EsSalud) cubre atenciones de enfermedades y accidentes comunes. Sin embargo, estudios previos en profesionales de la salud peruana, han señalado que los accidentes y enfermedades de origen ocupacional son frecuentes en este grupo profesional, y muchas veces son desatendidos por los empleadores ${ }^{(2,3)}$.

En 1998 se publicó la Norma Técnica del Seguro Complementario de Trabajo de Riesgo (SCTR), en la cual se establece la cobertura de accidentes de trabajo y enfermedad profesional de manera obligatoria para todos los trabajadores. Esta norma contempla atenciones desde la prevención hasta la rehabilitación, así como indemnizaciones y cobertura total de los tratamientos que se requiera. Este seguro, además, alcanza a todas las actividades descritas en el Anexo 5 del Reglamento de la Ley de Modernización de la Salud de la Seguridad Social, dentro de la cual se encuentran servicios médicos, odontológicos y otras actividades relacionadas con la salud humana (4). Asimismo, la Ley de Seguridad y Salud en el trabajo establece que el empleador asume las implicancias económicas, legales y de cualquier otra índole a consecuencia de un accidente o enfermedad que sufra el trabajador en el desempeño de sus funciones, o a consecuencia de él, y que el trabajador tiene derecho a las prestaciones de salud necesarias y suficientes hasta su recuperación y rehabilitación, procurando su reinserción laboral. La cobertura abarca también toda actividad que se desarrolle durante la ejecución de

\footnotetext{
Servicio de Salud Ocupacional Cobriza, Doe Run Perú. Huancavelica, Perú.

2 Centro Médico Ocupacional Laboral Care SST. Huancayo, Perú.

a Médico, diplomado en medicina ocupacional y medio ambiente; ${ }^{\mathrm{b}}$ médico, especialista en medicina ocupacional y medio ambiente. Recibido: 03-08-13 Aprobado: 07-08-13
}

Citar como: Landa-Romero M, Ramos-Ascona C, Hidalgo-Contreras S. Seguro complementario de trabajo de riesgo en personal de salud [carta]. Rev Peru Med Exp Salud Publica. 2013;30(3):530. órdenes del empleador, o durante la ejecución de una labor bajo su autoridad, o en el desplazamiento de la misma, aun fuera del lugar y horas de trabajo ${ }^{(5)}$.

Queda claro, entonces, que los empleadores públicos y privados están en la obligación de brindar al personal de salud un seguro contra accidentes de trabajo $y$ enfermedades profesionales, el cual debe estar vigente desde el primer día de labores. Además, los empleadores tienen el deber de informar y capacitar a sus trabajadores sobre los riesgos a los que estarán expuestos en el trabajo.

Actualmente se desconoce la cobertura de los trabajadores de salud con el SCTR, a pesar de ser los más expuestos a sufrir accidentes y enfermedades ocupacionales dentro de todos los grupos ocupacionales. Es de gran necesidad que tanto el personal de salud como los directivos conozcan la Ley de Seguridad y Salud en el Trabajo para exigir su cumplimiento y poder proteger a los trabajadores de los riesgos ocupacionales. Es preocupante, también, que no exista una gestión adecuada de seguridad y salud ocupacional en el primer nivel de atención, siendo los trabajadores que tienen mayor riesgo de accidentes ${ }^{(3)}$.

Fuentes de financiamiento: autofinanciado.

Conflictos de interés: los autores declaran no tener conflictos de interés.

\section{REFERENCIAS BIBLIOGRÁFICAS}

1. Mejía C, Quiñones-Laveriano D, Espinoza K, QuezadaOsoria C. Deficiente cobertura de aseguramiento en médicos durante el servicio rural y urbano-marginal en salud. Rev Peru Med Exp Salud Publica. 2013;30(2):220-3.

2. Cabezas C. Tuberculosis en personal y estudiantes de salud: un tema pendiente para los servicios de salud y la universidad. Rev Peru Med Exp Salud Publica. 2012;29(2):179-80.

3. Sociedad Peruana de Salud ocupacional. La gestión de los accidentes de trabajo en trabajadores de salud: a propósito de un caso [Internet]. Lima: SOPESO [citado el 18 de julio de 2013]. Disponible en: http://sopeso.org/admin/files/ archivos/02112012140048_sopeso_25.pdf

4. Perú, Congreso de la Republica. Norma Técnica del Seguro Complementario de Trabajo de Riesgo. Decreto Supremo 003-98-SA. 13 de abril de 1998.

5. Perú, Congreso de la Republica. Ley 29783. Ley de Seguridad y Salud en el Trabajo. 20 de agosto 2011.

Correspondencia: Manuel Landa Romero.

Dirección: Urb. Enrique Rosado Dpto. 404 I Etapa, Huancayo, Perú. Teléfono: (51) 940421210

Correo electrónico:manuel.landa.romero@gmail.com 